\title{
A monoclonal antibody to an antigen present on the microvillous membrane of the trophectoderm of the preimplantation blastocyst of the pig
}

\author{
A. Whyte, M. Bacon and S. Ellis \\ A.F.R.C. Institute of Animal Physiology, Babraham, Cambridge CB2 4AT, U.K.
}

\begin{abstract}
Summary. Immunization of BALB/c mice with 14-day pig preimplantation blastocyst material followed by fusion of spleen cells with NS- 0 myeloma cells resulted in a clone, $\mathrm{SN} 1 / 38$, which secreted $\mathrm{IgG}_{1}$ which reacted specifically with the microvillous border of the pig trophectoderm and trophoblast as assessed by immunohistology. SN1/38 did not react with other fetal tissues, or with blastocysts from other animal species. It was shown by absorption studies and by enzyme-linked immunoabsorbent assay that SN1/38 was not directed against the placental form of pig alkaline phosphatase. The location of this antigen and its apparent presence throughout gestation indicate a functional role in the materno-fetal interaction.
\end{abstract}

\section{Introduction}

Placentation in mammals shows wide morphological diversity. Placentae have been categorized as varying from non-invasive (e.g. pig) to migratory (e.g. sheep) to invasive (e.g. man) (for review see Steven, 1983). In spite of this extended array of different morphologies, the immunological paradox of the survival of the demonstrably allogeneic fetus is a 'problem' surmounted by all species. It is not unreasonable to postulate that, in view of the similarity of the immune system between different mammals, there may be a common mechanism amongst species that prevents maternal immunological rejection of the fetus. Many hypotheses have been advanced as to the nature of this mechanism, but few have stood the test of time. Current opinion seems to favour a 'priming' of the maternal immune system, probably at the level of the regional lymph nodes draining the gravid uterus (Newport \& Carter, 1983). Such priming involves antigen-presenting cells entering via the afferent lymphatic and/or the lymphocytes entering the node from the blood, the result being a carefully regulated response by the mother leading to tolerance. Also suggested as a means of allowing survival in utero is the absence of MHC (Major Histocompatibility Complex) products on the trophoblast, the site of materno-fetal contact. These gene products control self/non-self recognition reactions and in man they are HLA-A, HLA-B, HLA-C and HLA-D. They are also associated with a small molecule in the cell surface, $\beta_{2}$-microglobulin. Several reports have shown that HLA and $\beta_{2}$-microglobulin are absent from human villous trophoblast (Faulk \& Temple, 1976; Goodfellow, Barnstable, Bodmer, Snary \& Crumpton, 1976). However, human non-villous trophoblast expresses a Class I MHC molecule which is not HLA-A or HLA-B (Redman, Stirrat \& Sunderland, 1983). The mouse placenta appears to have Class I but not Class II antigens on its trophoblast (Billington \& Bell, 1983). For the pig, $\beta_{2}$-microglobulin has been reported on preimplantation blastocysts (Meziou, Chardon, Fléchon, Kalil \& Vaiman, 1983). In spite of this relatively unclear picture of Class I and Class II MHC antigenic expression by trophoblasts of different species, there is increasing evidence that tissue-specific antigens are present on this epithelium (Searle \& Jenkinson, 1978; Whyte \& Loke, 1979; Johnson, Cheng, Molloy, Stern \& 
Slade, 1981). These antigens may be of relevance to the immunological survival of the fetus and we have chosen to study the pig in which early embryonic mortality may be as high as $40 \%$, and the immunology of this economically important embryo loss is undefined.

\section{Materials and Methods}

\section{Animals and recovery of blastocysts}

Large White Devana sows and gilts were taken from the Institute herd and killed by captive bolt and exsanguination at known stages of pregnancy. Material from 2 animals at Day 14 of pregnancy (day of mating $=$ Day 0 ) was used to raise the monoclonal antibodies. Other materials used in the immunohistology were obtained from animals at 9-18 days and on the 66th day of pregnancy. The reproductive tract was removed aseptically at laparotomy and placed in a sterile container before transportation to the laboratory. Para-aortic lymph nodes (PALN), which drain the gravid uterus, were also obtained at laparotomy. After removal of the ovaries, each horn was dissected free of the broad ligament and separated just above the cervix. A sterile glass tube was inserted into this end of the horn and secured with a ligature. Into the other end of the horn $20 \mathrm{ml}$ Hank's Balanced Salts Solution (HBSS) (Flow Laboratories, Irving, U.K.) at $37^{\circ} \mathrm{C}$ were slowly introduced. The uterus was gently manipulated so that the bolus passed down and was collected into a sterile container. Sheep material was obtained in a similar manner, i.e. by flushing. Horse and guinea-pig material was obtained by dissecting the uterus around blastocystic swellings. Human material was obtained after delivery or following therapeutic terminations of pregnancy.

\section{Production of antibody}

Four BALB/c mice were immunized 7 days apart by two i.p. injections of mechanically dissociated 14-day blastocysts (avoiding the embryonic disc region) in sterile saline $(9 \mathrm{~g} \mathrm{NaCl} / 1)$. After 5 days blood was collected from the tail veins and the sera tested against solubilized ( $1 \%$ Nonidet P-40 in PBS: phosphate-buffered saline) 14-day-old pig blastocyst material by double radial immunodiffusion. The mouse that responded with the greatest intensity of precipitin line was selected, and the spleen cells were fused with cells from the mouse myeloma cell line NS-0 (a mutant of X-63 which does not produce $\kappa$ chain) using polyethylene glycol (PEG 1500) by the method of Köhler \& Milstein (1975). A monoclonal antibody SN 1/38 was obtained after sequential dilution cloning in the presence of irradiated (200 rad) BALB $/ \mathrm{c}$ mouse spleen feeder cells $\left(10^{6} / \mathrm{ml}\right)$ at a limiting dilution of one cell per flat-bottomed microtitre well. The cells were grown in RPMI 1640 medium containing $10 \%$ FCS (fetal calf serum), glutamine and HAT (hypoxanthine/aminopterin/ thymidine); then weaned into hypoxanthine/thymidine and then RPMI medium alone.

\section{Immunohistology}

Small samples of tissue or flushed blastocysts were fixed in cold methanol or acetone overnight at $4^{\circ} \mathrm{C}$ before embedding in low melting-point wax. This method gave excellent preservation of tissue and was shown, by comparison with cryostat sections and by use of indirect immunoperoxidase methods, to retain antigenic activity. Clone supernatants were routinely screened on thin sections $(7-10 \mu \mathrm{m})$ of 14-day-old elongated blastocysts. The immunohistological procedure involved pretreatment with normal pig serum ( $2 \%$ in PBS), incubation with the clone supernatant (titrated to optimal dilution, normally $1: 10$ to $1: 20$ ) for $60 \mathrm{~min}$ at $37^{\circ} \mathrm{C}$, and then addition of porcine anti-mouse-immunoglobulin-FITC (fluorescein isothiocyanate) at $1: 40$ in PBS for $30 \mathrm{~min}$ at $37^{\circ} \mathrm{C}$. Between stages the sections were exhaustively washed with PBS. Controls were performed with normal mouse serum as the primary immunoglobulin stage. Sections were mounted and examined on a Leitz Diavert inverted microscope using epi-illumination fluorescence, occasionally with propidium iodide nuclear counterstain for localization of the nuclei of the cells (Ockleford et al., 
1981). Photographs were taken using an Olympus OM2 camera on Kodak XP-1 film rated at 1600 ASA. Fluorescent reaction was verified using an indirect immunoperoxidase method. More than 160 blastocysts at preimplantation stages of gestation were examined.

\section{Enzyme-linked immunoassay}

The enzyme-linked immunoabsorbent assay (ELISA) was performed in Nunc Immunoplates II. Wells were coated with a preparation of placental alkaline phosphatase from pig at $5 \mu \mathrm{g} / \mathrm{ml}(100$ $\mu \mathrm{l} /$ well) at $4^{\circ} \mathrm{C}$ overnight. The optimal concentration of pig placental alkaline phosphatase (EC 3.1.3.1) was chosen by titration and the enzyme was purified, from a product obtained from Sigma (Type XVI), by column chromatography. It gave a single band after sodium dodecyl sulphate (SDS)-electrophoresis and also showed a histochemical reaction for alkaline phosphatase after agarose gel electrophoresis. The wells were rinsed three times in PBS containing $0.05 \%$ Tween with $2 \%$ normal rabbit serum (NRS) and $0 \cdot 1 \%$ sodium azide. Blocking solution (200 $\mu 1$ PBS containing $0.5 \%$ Tween, $10 \% \mathrm{NRS}$ and $0 \cdot 1 \% \mathrm{NaN}_{3}$ ) was added to each well and left for $1 \mathrm{~h}$ at room temperature. After rinsing as before, culture supernatant SN $1 / 38$ was added in PBS with $2 \%$ NRS and $0 \cdot 1 \% \mathrm{NaN}_{3}$ at $100 \mu \mathrm{l} /$ well and left for $1 \mathrm{~h}$ at room temperature with shaking. After washing, rabbit anti-mouse IgG-peroxidase (from Miles Laboratories) $(100 \mu \mathrm{l})$ was added. This was made up at $1: 1000$ dilution in PBS with $2 \% \mathrm{NRS}$ and $0.1 \% \mathrm{NaN}_{3}$. This was left for $1 \mathrm{~h}$ at room temperature on the shaker. After washing, $200 \mu$ l substrate solution were added to each well. The substrate solution was made up freshly by mixing $18 \mathrm{ml}$ distilled water, $2 \mathrm{ml}$ stock solution A (1 M-sodium acetate/citrate acid buffer pH 6.0), $0.2 \mathrm{ml}$ stock solution B (10 mg tetramethylbenzidine $/ \mathrm{ml}$ dimethylsulphoxide) and $20 \mu \mathrm{l} 6 \% \mathrm{H}_{2} \mathrm{O}_{2}$. The colour reaction was stopped after $5 \mathrm{~min}$ by addition of $50 \mu \mathrm{l} 3 \mathrm{M}_{-} \mathrm{H}_{2} \mathrm{SO}_{4}$, and the absorbance at $450 \mathrm{~nm}$ was read on a Titertek Multiscan MC ELISA reader. Serial doubling dilution titrations of SN1/38 were performed to determine the optimal concentration. Samples of alkaline phosphatases from Sigma were also tested by ELISA against SN1/38. The placental forms were from man (Type XXIV) and cow (Type XV) and the intestinal forms from pig (Type IV) and calf (Type 1-S). All were tested for alkaline phosphatase enzymic activity using the protocol in Sigma Technical Bulletin 710-EP which involves a colorimetric method with 5-bromo-4-chloro-3-indolyl phosphate as substrate.

\section{Results}

Clones grew in 25 of the 48 wells into which the fused cells were seeded. The medium from each well was aspirated at frequent intervals and assayed for anti-pig blastocyst activity using indirect immunofluorescence on sections of 14-day blastocysts. Four clones were found to react with the blastocysts: $\mathrm{SN} 1 / 17 ; \mathrm{SN} 1 / 20 ; \mathrm{SN} 1 / 35$ and $\mathrm{SN} 1 / 38$. The last of these gave a highly specific reaction with the microvillous membrane of the trophectoderm and was consequently selected for limiting dilution cloning. It was a derivative of this original clone, $\mathrm{SN} 1 / 38.1 .1$ which is reported here, but for convenience we shall call it $\mathrm{SN} 1 / 38$. The antibody produced is an $\mathrm{IgG}_{1}$ as identified using a mouse monoclonal typing kit (Serotec).

The pattern of immunofluorescence of $\mathrm{SN} 1 / 38$ with a thin section of a blastocyst is shown in $\mathrm{Pl}$. 1, Fig. 1. There was a marked reaction to the outside of the trophectoderm (that part which will form a microvillous interdigitation with the endometrium after Day 18 of pregnancy) but no reaction inside the trophectodermal cells or in the endoderm. The antigenic epitope recognized by SN1/38 was also present at Day 66 of gestation, and possibly at greater density judging by the intensity of fluorescence (P1. 1, Fig. 2).

Cells were mechanically dissociated from the placenta of a 66-day-pregnant animal by passage through 19- and 25-gauge needles, and labelled with SN1/38 and FITC-conjugated goat anti-mouse immunoglobulin. The fluorescence was not spread evenly over the membranes of the cells, but was 
located in certain regions predominantly at areas of cell-to-cell contact (P1. 1, Fig. 3). Some cells did, however, show a more general membrane fluorescence (PI. 1, Fig. 4), but this type of cell was only seen either singly or in association with a totally non-fluorescent cell (Pl. 1, Fig. 4, arrow).

The species and tissue specificities of the epitope recognized by $\mathrm{SN} 1 / 38$ are demonstrated in Table 1. Clone SN1/38 bound to pig trophectoderm and trophoblast at all stages of pregnancy tested, but did not react with fetal skin, kidney and spleen, and did not recognize determinants on tissues from any of the other species tested (Table 1).

Samples of pig, human and bovine placental alkaline phosphatase and pig and bovine intestinal alkaline phosphatase were immobilized on Nunc Immunoplates and the binding of the SN1/38 supernatant to them was assayed by ELISA. Human serum albumin was also immobilized and a hyperimmune polyclonal antiserum to it was used as a positive control. Negative controls included using normal rabbit serum and BSA with the SN1/38 supernatant. Other controls involved replacing the $\mathrm{SN} 1 / 38$ with the supernatant from a fusion supernatant which was histologically negative with blastocysts, and omitting the peroxidase-conjugated antibody. The results are presented in Table 2. In no case was there significant binding of the SN1/38 supernatant, indicating that the epitope recognized was not on pig placental alkaline phosphatase or secreted into serum or urine.

To confirm the results of the ELISA, pig placental alkaline phosphatase was immobilized by conjugation to $\mathrm{CNBr}$-activated Sepharose $4 \mathrm{~B}$ using the protocol detailed by Pharmacia. After washing, the beads were added to SN1/38 supernatant and left overnight with gentle rotation. The beads were pelleted and the supernatant used in indirect immunofluorescence with 14-day pig blastocysts. There was no reduction in fluorescence compared with the supernatant before

Table 1. The reaction of the $\mathrm{SN} 1 / 38$ antiserum by indirect immunofiuorescence with various pig tissues and trophoblast material of other species

\begin{tabular}{|c|c|c|c|}
\hline Species & Tissue & Day of gestation & $\begin{array}{c}\text { Intensity of fluorescence } \\
(- \text { to }+++)\end{array}$ \\
\hline \multirow[t]{7}{*}{ Pig } & Trophectoderm & $\begin{array}{l}9 \text { (pre-elongation) } \\
11 \text { (elongating) } \\
14 \text { (post-elongation) } \\
16 \\
17 \\
18 \text { (implantation) }\end{array}$ & $\begin{array}{l}+++ \\
+++ \\
+++ \\
+++ \\
+++ \\
+++\end{array}$ \\
\hline & $\begin{array}{l}\text { Trophoblast } \S \\
\text { 'Trophospheres'* }\end{array}$ & $\begin{array}{l}66 \\
14(+7) \\
14(+10)\end{array}$ & $\begin{array}{l}+++ \\
++t \\
+++\end{array}$ \\
\hline & Endometrium & 14 & - \\
\hline & Para-aortic lymph node & 14 & - \\
\hline & Fetal skin§ & 66 & - \\
\hline & Fetal kidney§ & 66 & - \\
\hline & Fetal spleen§ & 66 & - \\
\hline Guinea-pig & Trophoblast & $\begin{array}{l}21 \\
44\end{array}$ & - \\
\hline Man & Trophoblast & $\begin{array}{l}\text { First trimester† } \\
\text { Full term } \ddagger\end{array}$ & - \\
\hline & Trophectoderm & 14 & - \\
\hline \multirow[t]{4}{*}{ Donkey } & Girdle & 33 & - \\
\hline & Endometrial cup tissue & $33 \& 34$ & - \\
\hline & Trilaminar yolk-sac & $32 \& 33$ & - \\
\hline & Bilaminar yolk-sac & 33 & - \\
\hline
\end{tabular}

* These are spheres derived after several days culture of dissociated 14-day blastocysts.

+ Approximately 8-12 weeks of gestation.

₹ At delivery, approximately $\mathbf{4 0}$ weeks of gestation.

$\S$ Tissues derived from the same conceptus. 

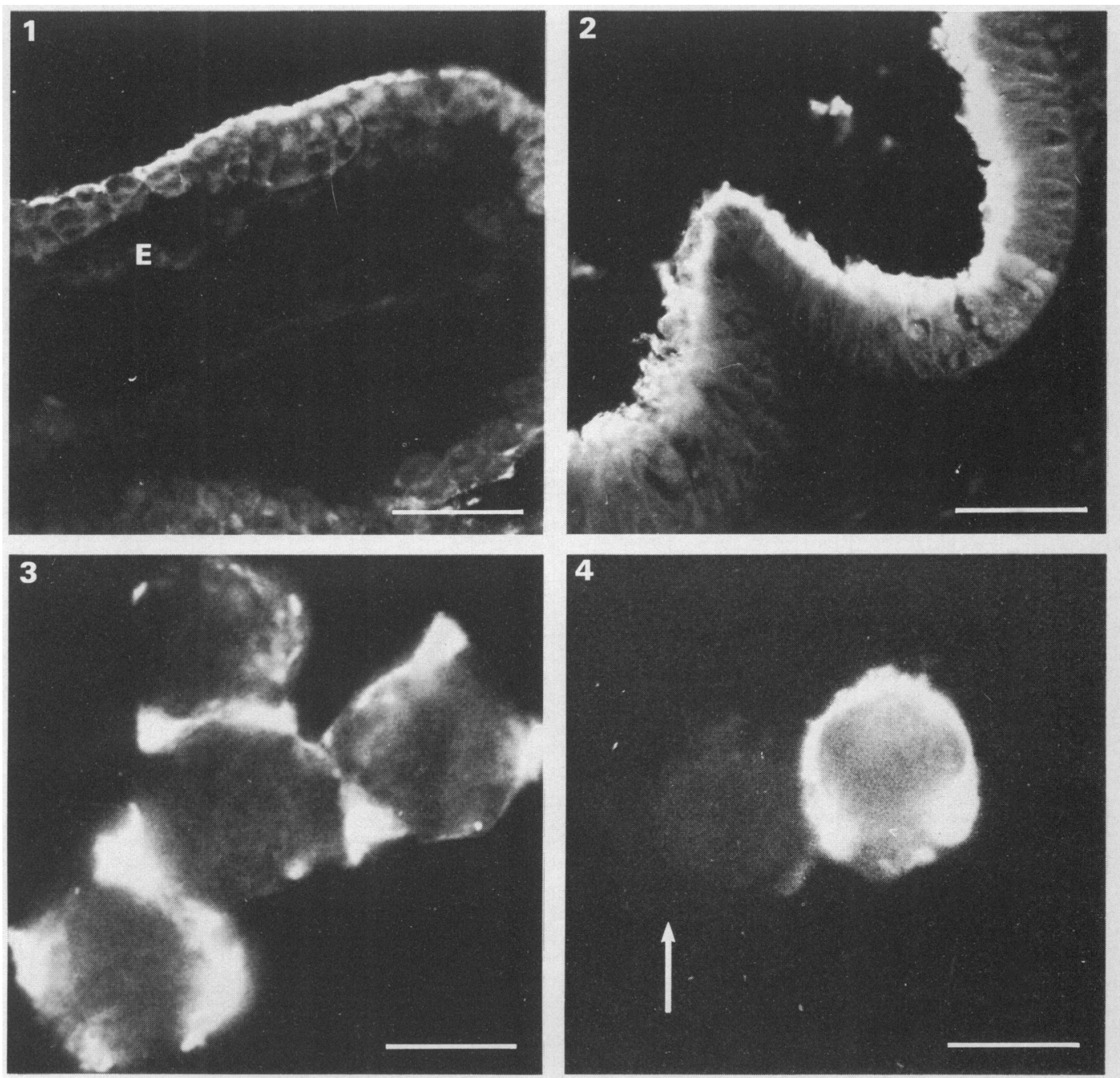

Fig. 1. Indirect immunofluorescent staining with the $\mathrm{SN} 1 / 38$ monoclonal antibody of a thin section through a pig blastocyst at 14 days. There was marked fluorescence of the microvillous border of the trophectoderm but no reaction inside the trophectodermal cells or in the endoderm (E). The bar represents $40 \mu \mathrm{m}$.

Fig. 2. The reaction of $\mathrm{SN} 1 / 38$ with the fetal aspect of the placenta from a 66-day-pregnant pig. There was marked fluorescence of the trophoblast membrane. In this section the fetal trophoblast had separated from the maternal endometrium. The bar represents $40 \mu \mathrm{m}$.

Fig. 3. Cells mechanically dissociated from the placenta of a 66-day-pregnant animal and stained with $\mathrm{SN} 1 / 38$. Fluorescence appeared to be largely concentrated at areas of cell-cell contact. The bar represents $20 \mu \mathrm{m}$.

Fig. 4. Two cells from the same placenta as shown in Fig. 3. The right-hand cells shows a general membrane fluorescence whereas the left-hand cell (arrow) is non-fluorescent. The bar represents $20 \mu \mathrm{m}$. 
Table 2. Results of enzyme-linked immunoabsorbent assays with $\mathrm{SN} 1 / 38$ supernatant: the wells were coated with the substances listed in the first column, the primary antibody is listed in the second column, and the second antibody was anti-rabbit or anti-mouse immunoglobulin conjugated to peroxidase

\begin{tabular}{|c|c|c|}
\hline Coating & Primary antibody & $\mathbf{E}_{450^{*}}^{*}$ \\
\hline Human serum albumin (HSA-Sigma) & Rabbit anti-HSA (Nordic) & $0.577 \pm 0.012$ \\
\hline Human serum albumin & SN $1 / 38$ & $0.154+0.004$ \\
\hline Bovine serum albumin (BSA-Sigma) & $\mathrm{SN} 1 / 38$ & $0.153 \pm 0.005$ \\
\hline \multicolumn{3}{|l|}{ Alkaline phosphatases } \\
\hline Pig placental & SN1/38 & $0.156 \pm 0.004$ \\
\hline Pig intestinal & $\mathrm{SN} 1 / 38$ & $0.154 \pm 0.002$ \\
\hline Bovine placental & SN1/38 & $0.155 \pm 0.003$ \\
\hline Calf intestinal & SN1/38 & $0.156 \div 0.004$ \\
\hline Human placental & SN1/38 & $0.156+0.003$ \\
\hline Pig placental & SN1/7† & $0.155 \pm 0.003$ \\
\hline Pig placental & $\mathrm{SN} 1 / 38 \ddagger$ & $0.155 \pm 0.002$ \\
\hline \multicolumn{3}{|l|}{ Pig pregnancy urine } \\
\hline 4-day & SN1/38 & $0.157 \pm 0.003$ \\
\hline 6-day & SN1/38 & $0.155 \pm 0.004$ \\
\hline 7-day & $\mathrm{SN} 1 / 38$ & $0.155+0.004$ \\
\hline \multicolumn{3}{|l|}{ Pig pregnancy serum } \\
\hline 10-day & SN $1 / 38$ & $0.154 \pm 0.002$ \\
\hline 14-day & $\mathrm{SN} 1 / 38$ & $0.155 \pm 0.003$ \\
\hline
\end{tabular}

Values are mean \pm s.e.m. for at least 30 observations of each.

None of the samples tested had binding significantly above background, whereas a hyperimmune polyclonal anti-human serum albumin showed positive binding.

* Absorbance at $450 \mathrm{~nm}$.

$\dagger$ Histologically non-reactive clone supernatant.

$\ddagger$ Second antibody (peroxidase conjugate) omitted.

absorption. A range of doubling dilutions of the primary antibody were used in both cases so that this test spanned the fluorescence end-point.

\section{Discussion}

The data presented here indicate that there is an antigen present on the placental trophoblast of the pig at the site of maternal-fetal contact and which is absent from the other tissues of the pig which were studied. The observations that it is located on the microvillous border of the trophectoderm, i.e. in direct contact with maternal tissue, and that it is present at all the stages of gestation studied, including preimplantation stages, suggest a role for this antigen in the materno-fetal interaction.

Although placentation in the pig is restricted to microvillous interdigitation (Steven, 1983), the trophectoderm, and later the trophoblast, must play a role in the transport of substances to the developing fetus. The fact that $\mathrm{SN1} / 38$ antiserum recognizes an antigen on pre-elongation (Day 9) as well as on post-elongation ( $>$ Day 12) blastocysts (Table 1) indicates that the antigen is not involved in the elongation process. SN1/38 did not react with uterine flushings indicating that it was not directed towards polypeptides released by preimplantation pig blastocysts (Godkin, Bazer, Lewis, Geisert \& Roberts, 1982), although the concentration may be too low in flushings to be detectable. The absence of binding of $\mathrm{SN} 1 / 38$ to pregnant pig endometrium (Table 1 ) also suggests that it is not the purple protein (uteroferrin) thought to be responsible for iron transport from the mother to the fetus (Basha, Bazer \& Roberts, 1979). Certainly the SN1/38 antigen does not appear to be secreted, at least in early pregnancy, because it is absent from serum and urine (Table 2). Because it was also absent from the para-aortic lymph nodes (Table 1) that drain the gravid uterus, 
it appears that the antigen does not dissociate from the trophectoderm or else it is not 'trapped' in the regional lymph nodes. This observation also suggests that it is not a trophoblast-lymphocyte cross-reactive antigen such as has been described for the human (Faulk \& Hsi, 1983). A role for the SN1/38 antigen in attachment is possible in view of the fact that it appears before implantation and is maintained throughout a substantial period of pregnancy. It is also present on 'trophospheres' after 10 days in culture, suggesting that its synthesis is controlled by the blastocyst itself and is not regulated by a maternal factor. This would indicate that it is not a modulating antigen which induces tolerance by responding to maternal immunoglobulins directed towards it.

The epitope is species-specific (Table 1), although it is impossible with one monoclonal antibody to know whether the antigen itself is species-specific. Mouse and human trophoblast have been shown, by use of polyclonal antisera, to possess species-specific antigens (Searle, Billington, Whyte \& Loke, 1981).

It is acknowledged that the trophoblast expresses antigenic products demonstrable in xenogeneic systems and which are tissue-specific (Searle \& Jenkinson, 1978; Whyte \& Loke, 1979). In man one of these antigens is probably the transferrin receptor (Booth \& Booth, 1982). Another is the placental form of the alkaline phosphatase enzyme. Antibodies to placental alkaline phosphatase are a major component of antisera raised against human trophoblast plasma membranes (Kantor, Galbraith, Emerson \& Galbraith, 1981). In the case of SN1/38, however, the epitope does not appear to be on pig placental alkaline phosphatase. Antiserum to human placental alkaline phosphatase inhibits the mixed lymphocyte culture (MLC) reaction (Kantor, Galbraith, Emerson \& Galbraith, 1983) in a way similar to that induced by antiserum to HLA-D, although with different dose-response and time-course characteristics (Kantor et al., 1983). Antisera to normal human serum and to transferrin had no effect on the MLC (Kantor et al., 1983). McIntyre \& Faulk (1979a, b) showed that trophoblast membranes, and antisera raised to them, blocked the allogeneically stimulated MLC reaction, but had no effect on mitogen-treated lymphocytes. These are in-vitro experiments, however, and there is no evidence that these observations have any analogous in-vivo correlate. These are also non-specific MLC experiments. In spite of these reservations, however, it is possible that substances on the trophoblast membrane could have an important role in the materno-fetal immunological interaction. The discovery of a trophoblastspecific antigen in the pig may further advance our understanding of pregnancy in this animal.

We thank Mr Jack Smith for pig management, Mr Rod Ash M.R.C.V.S. for veterinary assistance, Mr Ian King for histological service, Dr W. R. Allen for equine material and Dr G. Galfré for the NS-0 cell line. Human placental material was obtained from the Royal Marsden Hospital, London, and Addenbrooke's Hospital, Cambridge.

\section{References}

Basha, A.M.M., Bazer, F.W. \& Roberts, R.M. (1979) The secretion of an uterine specific, purple phosphatase by cultured explants of porcine endometrium. Dependency upon the state of pregnancy of the donor animal. Biol. Reprod. 20, 431-441.

Billington, W.D. \& Bell, S.C. (1983) Immunobiology of mouse trophoblast. In Biology of Trophoblast, pp. 571-595. Eds Y. W. Loke \& A. Whyte. Elsevier, Amsterdam.

Booth, C.M. \& Booth, A.G. (1982) Immunoelectrophoretic evidence that the human syncytiotrophoblast transferrin receptor is identical to a major plasma membrane antigen present throughout pregnancy. Placenta 3, 57-66.

Faulk, W.P. \& Hsi, B.-L. (1983) Immunobiology of human trophoblast membrane antigens. In Biology of
Trophoblast, pp. 535-570. Eds Y. W. Loke \& A. Whyte. Elsevier, Amsterdam.

Faulk, W.P. \& Temple, A. (1976) Distribution of $\beta 2$ microglobulin and HLA in chorionic villi of human placentae. Nature, Lond. 262, 799-802.

Godkin, J.D., Bazer, F.W., Lewis, G.S., Geisert, R.D. \& Roberts, R.M. (1982) Synthesis and release of polypeptides by pig conceptuses during the period of blastocyst elongation and attachment. Biol. Reprod. 27, 977-987.

Goodfellow, P.N., Barnstable, C.J., Bodmer, W.F., Snary, D. \& Crumpton, M.J. (1976) Expression of HLA system antigens on placenta. Transplantation 22, 593603.

Johnson, P.M., Cheng, H.M., Molloy, C.M., Stern, C.M.M. \& Slade, M.B. (1981) Human trophoblast- 
specific surface antigens identified using monoclonal antibodies. Am. J. Reprod. Immunol. 1, 246-254.

Kantor, R.R.S., Galbraith, R.M., Emerson, D.L. \& Galbraith, G.M.P. (1981) Placental alkaline phosphatase is a major specificity in antisera raised to human trophoblast membranes. Am. J. Reprod. Immunol. 1, 336-339.

Kantor, R.R.S., Galbraith, R.M., Emerson, D.L. \& Galbraith, G.M.P. (1983) Inhibition of lymphocyte activation by antisera to embryonic antigens shared with human placental trophoblast. Am. J. Reprod. Immunol. 3, 114-118.

Köhler, G. \& Milstein, C. (1975) Continuous cultures of fused cells secreting antibody of predefined specificity. Nature, Lond. 256, 495-497.

McIntyre, J.A. \& Faulk, W.P. (1979a) Antigens of human trophoblasts: effects of heterologous antitrophoblast sera on lymphocyte responses in vitro. $J$. exp. Med. 149, 824-836.

McIntyre, J.A. \& Faulk, W.P. (1979b) Trophoblast modulation of maternal allogeneic recognition. Proc. natn. Acad. Sci. U.S.A. 76, 4029-4032.

Meziou, W., Chardon, P., Fléchon, J.E., Kalil, J. \& Vaiman, M. (1983) Expression of $\beta_{2}$-microglobulin on preimplantation pig embryos. J. Reprod. Immunol. 5, 73-80.

Newport, A. \& Carter, J. (1983) Changes in T and B lymphocyte populations in the lymph nodes draining the uterus in pregnant mice. $J$. Reprod. Fert. 67, 433440.
Ockleford, C.D., Hsi, B., Wakely, J., Badley, R.A., Whyte, A. \& Faulk, W.P. (1981) Propidium iodide as a nuclear marker in immunofluorescence. I. Use with tissue and cytoskeleton studies. J. Immunol. Meth. 43, 261-267.

Redman, C.W.G., Stirrat, G.M. \& Sunderland, C.A. (1983) The expression of class I major histocompatibility complex (MHC) antigens by human nonvillous trophoblast. J. Reprod. Immunol., Suppl. 64A, Abstr.

Searle, R.F. \& Jenkinson, E.J. (1978) Localization of trophoblast-defined surface antigens during early mouse embryogenesis. J. Embryol. exp. Morphol. 43, 147-156.

Searle, R.F., Billington, W.D., Whyte, A. \& Loke, Y.W. (1981) Detection of human and murine trophoblastspecific antigens and an assessment of their species specificity. Placenta 2, 93-104.

Steven, D.H. (1983) Interspecies differences in the structure and function of trophoblast. In Biology of Trophoblast, pp. 111-136. Eds Y. W. Loke \& A. Whyte. Elsevier, Amsterdam.

Whyte, A. \& Loke, Y.W. (1979) Antigens of the human trophoblast plasma membrane. Clin. exp. Immunol. 37, 359-366.

Received 22 December 1983 